\title{
FAST examination diagnosing bladder rupture following blunt pelvic trauma
}

\author{
Kevin Bain, Vickie Kassapidis, Vadim Meytes, Galina Glinik
}

General Surgery, NYU Langone Hospital - Brooklyn, Brooklyn, New York, USA

\section{Correspondence to} Dr Kevin Bain,

kevin.bain@nyumc.org

Accepted 20 February 2018

\section{DESCRIPTION}

A 52-year-old man presented as a level 2 trauma notification after a plywood fell on him from 15 feet. On presentation, he was evaluated according to Advanced Trauma Life Support (ATLS) protocol. Secondary survey was significant for suprapubic tenderness and abrasions to bilateral hips. A focused assessment with sonography in trauma (FAST) examination was performed, showing echogenic fluid filling the bladder (video 1).

A Foley catheter was placed, and gross haematuria was noted. X-ray in the trauma bay showed fractures of the left superior and inferior pubic rami (figure 1). Subsequently, a CT cystogram was performed which showed large clot within the bladder with small extraperitoneal extravasation (figure 2). The injury was managed with transurethral Foley and gentle irrigation.

The FAST examination provides a rapid bedside screening tool for intraperitoneal free fluid and solid organ injuries. Blood clots within an injured organ may have similar echogenicity to that of the parenchyma. The sensitivity for detection of solid organ injury is therefore more limited and ranges from $41 \%-44 \%{ }^{1}$

The bladder is well protected by the bony pelvis, making rupture relatively uncommon in blunt trauma. However, it remains an important injury to rule out because mortality rates can be as high as $22 \% .^{2}$ Pelvic fracture with associated gross haematuria is an indication for immediate cystography.

Blunt extraperitoneal bladder rupture should be treated conservatively, with non-operative management having comparable outcomes to primary repair. ${ }^{3}$ Relative contraindications to conservative

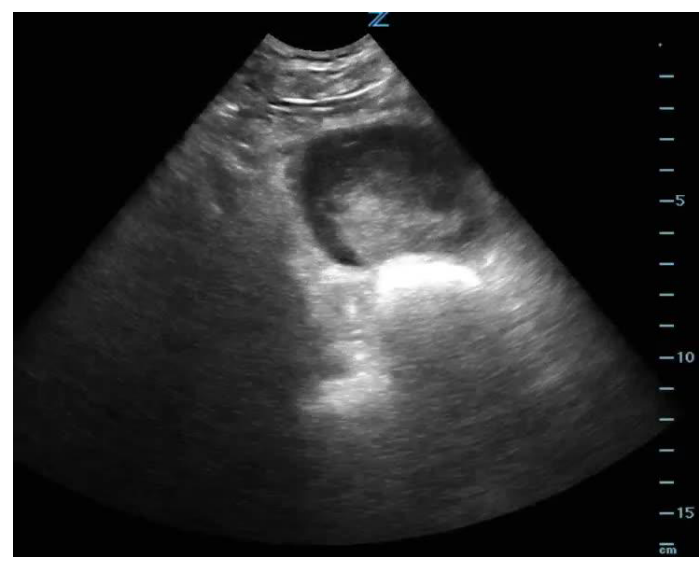

Video 1 Focused assessment with sonography in trauma examination performed in the trauma bay showing echogenic fluid filling the bladder.

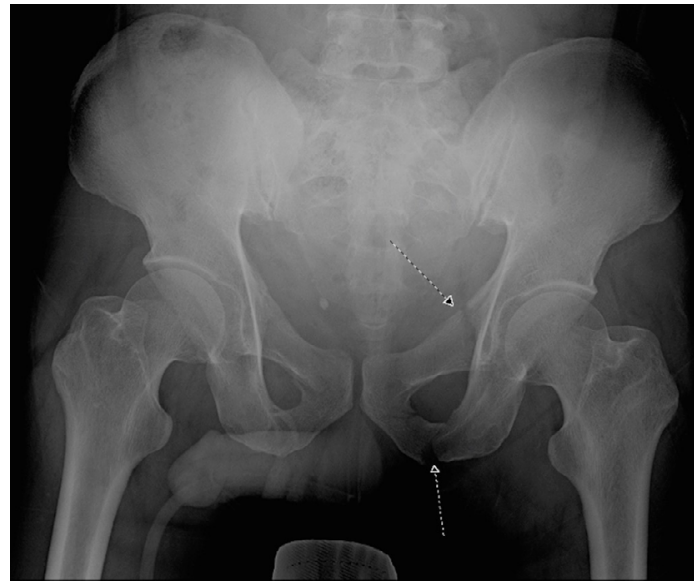

Figure 1 Mildly displaced fractures (arrows) involving the left superior and inferior pubic rami.

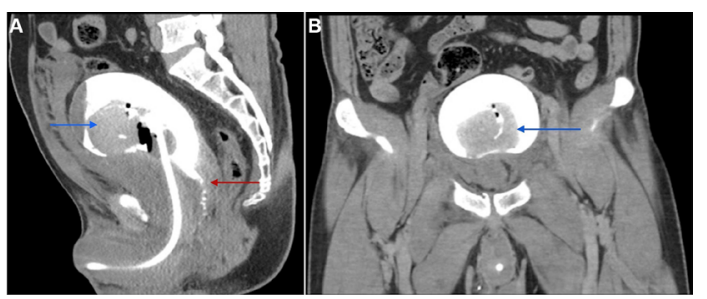

Figure 2 (A, B) CT cystography with a large clot within the bladder (blue arrow) and a small amount of extraperitoneal extravasation visible at the posterior aspect of the bladder (red arrow).

management of extraperitoneal bladder rupture include bone fragments protruding into the bladder, open pelvic fractures and concomitant rectal injuries. ${ }^{3}$ The use of transurethral catheters is preferred

\section{Learning points}

- Focused assessment with sonography in trauma examination is less sensitive for diagnosing solid organ injury and ranges from $41 \%-44 \%$.

- Haematuria and pelvic fractures are seen together in $90 \%$ of bladder ruptures. When both are present in blunt trauma, cystography should be performed.

- Extraperitoneal bladder injuries should be managed non-operatively with drainage using transurethral catheter alone. Intraperitoneal bladder injuries should be managed by primary repair with transurethral catheter or suprapubic tube drainage. 
over suprapubic catheters, resulting in fewer complications and fewer days of catheterisation. ${ }^{3}$

Contributors $\mathrm{KB}, \mathrm{VM}$, VK: writing and editing. $\mathrm{KB}, \mathrm{VM}, \mathrm{VK}$, GG: final editing and submission.

Funding This research received no specific grant from any funding agency in the public, commercial or not-for-profit sectors.

Competing interests None declared.

Patient consent Obtained.

Provenance and peer review Not commissioned; externally peer reviewed. (c) BMJ Publishing Group Ltd (unless otherwise stated in the text of the article) 2018. All rights reserved. No commercial use is permitted unless otherwise expressly granted.

\section{REFERENCES}

1 Richards JR, McGahan JP. Focused assessment with sonography in trauma (FAST) in 2017: What Radiologists Can Learn. Radiology 2017;283:30-48.

2 Iverson AJ, Morey AF. Radiographic evaluation of suspected bladder rupture following blunt trauma: critical review. World J Surg 2001;25:1588-91.

3 Holevar M. "Genitourinary trauma, management of." The eastern association for the surgery of trauma, 2004. www.east.org/education/practice-management-guidelines/ genitourinary-trauma-management-of

Copyright 2018 BMJ Publishing Group. All rights reserved. For permission to reuse any of this content visit http://group.bmj.com/group/rights-licensing/permissions.

BMJ Case Report Fellows may re-use this article for personal use and teaching without any further permission.

Become a Fellow of BMJ Case Reports today and you can:

- Submit as many cases as you like

- Enjoy fast sympathetic peer review and rapid publication of accepted articles

- Access all the published articles

- Re-use any of the published material for personal use and teaching without further permission

For information on Institutional Fellowships contact consortiasales@bmjgroup.com

Visit casereports.bmj.com for more articles like this and to become a Fellow 